\title{
Factual or Believable? Negotiating the Boundaries of Confirmation Bias in Online News Stories
}

\author{
David M. Murungi David J. Yates $\quad$ Sandeep Purao Yijie 'Joy' Yu Ruiting Zhan \\ Bentley University \\ Waltham, Massachusetts, USA \\ \{dmurungi, dyates, spurao\}@bentley.edu \\ \{yyujoy, zhanruit\}@gmail.com
}

\begin{abstract}
We examine the fake news phenomenon from a fresh perspective. Instead of assessing the factuality of news claims, our work explores the impact of these claims on reader beliefs. With the 2017 Alabama senate race as the empirical context, we examine how readers on both sides of the political spectrum evaluate online news stories considering their preconceived beliefs and values. Our analysis builds on concepts from argument and social representations theories to explore the role of argumentation in this process. We focus on detecting arguments in reader comments to depict challenges involved in reader consideration of newsworthy events and news stories. A key finding of the paper is that readers from both sides of the political spectrum appear to engage in similar strategies to confirm or negotiate acceptance or rejection of claims. The paper contributes to theory by depicting social representation as a process that mediates conflict in belief structures. We conclude by speculating about possibilities for future work, such as designing behavioral and technological interventions that can supplement fact-checking. An important goal here is to improve how we, in the presence of our biases, collectively consume online news stories and engage in the discourse that surrounds them.
\end{abstract}

\section{Introduction}

The "fake news" problem has been described as the dissemination of news stories that are intentionally and verifiably false, and could mislead readers [1]. The problem has been with us for centuries (ibid). The advent of social media has drastically escalated the scope of this concern. This was particularly evident in the aftermath of the 2016 U.S. presidential election when the phenomenon of "fake news" was widely attacked for its possible influence on the country's electoral process [1-3]. To address this problem, several fact-checking sites (e.g., snopes.com and politifact.com) as well as automated solutions (e.g., Hoaxy and Truthy) have been created [2]. Although these solutions are useful for establishing the facts [4], they do not question or explore the relationship between existing belief structures of readers and the claims expressed in reported news. This is particularly true for readers of news sources that are designed to 'confirm existing biases' $[5,6]$. We suspect that this is a key reason that fact-checking approaches continue to be ineffective in influencing readers' decisions to accept or reject news reports.

This rationale can be traced to the well-known notion of confirmation bias which has been demonstrated in studies that show how individuals tend to favor information that confirms their pre-existing beliefs and discount information that challenges these beliefs [7, 8, 39]. This is corroborated by findings that show that in the wake of a recent focus on misinformation emanating from the right, some conservative voters have become skeptical of the veracity of fact-checking sites [1]. This tendency to accept agreeable facts and to discount contrary facts means that the effectiveness of fact-checking tools in combating the growing occurrence and spread of fake news is likely to remain somewhat limited.

We suspect that confirmation bias, however, does not necessarily mean an unreasoned approach to the consumption of news stories, even in the aftermath of significant and relevant events. Instead, it could represent a deliberate decision by the reader to impose a greater burden of proof on foreign ideas or concepts. The negotiation of reasonable criteria for doubt remains a subjective process. Therefore, the mere flagging of a news story as false may not shift the belief structures of those reading the story because this abstract adjudication of the truth-claim does not engage the criteria that readers use to negotiate their beliefs. In this paper, we seek to extend the research on fake news by moving beyond such abstract adjudications to exploring the intersubjective processes involved in the acceptance or rejection of news claims.

To accomplish this, we employ the theory of social representations as well as argument theory to explore the delineation between deliberate (reasonable, wellargued) applications of confirmation bias and inadvertent (unreasonable, fallacious) manifestations of 
confirmation bias in the social representation of online news stories. The paper addresses the following research question: What role does argumentation play in partisan representations of reactions to newsworthy events and subsequent news stories?

To answer this question, the paper first introduces social representations and argument theories as the theoretical bases for the study and explains their relationship and unique perspectives on the phenomenon of fake news. It then proceeds to introduce the empirical context and methodology used to conduct the investigation. We then discuss the findings and conclude with implications for research as well as the development of new approaches to ameliorate the problems that arise from fake news.

\section{Theoretical background}

\subsection{Social representations theory}

Social representations theory originated with Moscovici [9-11] and is based on Durkheim's [12] distinction between collective and individual representations. Social representation emphasizes the collective understanding "of a social object by the community for the purpose of behaving and communicating" [11]. A social representation can also be defined as the "common sense" knowledge that people use to make sense of general topics (in our case online news stories) that are the focus of everyday conversation [13-15]. They provide a means through which people "make the unfamiliar familiar" because encounters with the unknown or the unrecognized can pose threats to shared and socially constructed realities $[16,17]$. The representation consequently functions as a "means of transferring what disturbs us, what threatens our universe, [to] a context where the unusual becomes usual, where the unknown can be included in an acknowledged category" [9].

The process through which this familiarization takes place involves two interdependent socio-cognitive processes: anchoring and objectification. Anchoring is the initial response to an unfamiliar phenomenon or event that involves an attempt to represent it in terms that are already understood [9] or 'anchoring' the new phenomenon in existing representational structures or classifications. This is illustrated in how the terrorist attacks on the World Trade Center were initially described in terms of previous major terrorist attacks before a representation known as " $9 / 11$ " emerged to distinguish this event from other terrorist activities [16]. The development of the new representation " $9 / 11$ " is known as 'objectification', which is defined as the sense-making process through which people reconstruct existing representations and form new ones as they 'concretize' $[9,18]$ their initial perceptions into an actual perception of the new phenomenon [19].

Social representations are also structured around a central core and some peripheral elements [20]. The central core provides a generating function through which the other elements obtain meaning and value and is viewed as "the most stable element of the representation, the one that ensures the perennial nature of the representation in moving and evolving contexts" [20]. Peripheral elements, on the other hand, are more malleable and can adapt based on new information or changes in the environment. Organized around the central core, peripheral elements function as a defense mechanism or 'shock absorber' as they are able to change without threatening the central core $[21,22]$.

Social representations theory therefore explains confirmation bias by suggesting that social beliefs can be represented in terms of a rigid core that has a higher threshold of proof prior to modification and peripheral elements that are more amenable to critical scrutiny and responsive to changes in the external environment. In our work, we employ these concepts, i.e. a rigid core of beliefs as well as peripheral elements, and explore how the boundaries between these may be negotiated as readers react to newsworthy events and online news stories, where their reactions are expressed in reader comments.

\subsection{Argument theory}

To examine how the social representations of beliefs are negotiated in response to significant events and the news stories that appear in their wake, we borrow from the theory of argumentation. An argument could "arguably" be construed as the fundamental building blocks of social representation belief structures because argument is generally accepted by argument theorists - dating as far back as Aristotle - to be a means of justifying knowledge claims [23-25]. Relatedly, as Hirschheim [26] records it, "The Greeks chose to classify knowledge into two types: doxa (that which was believed to be true) and episteme (that which was known to be true)." From this perspective, argumentation could be seen as the process of clarifying the relationship between "doxa" ("beliefs") and "episteme" ("truth" or "facts") with the desire to resolve the difference between the two providing the motivation for an argument or argumentation.

Argument theorists, therefore, agree with the assertion that argumentation arises in response to, or in anticipation of, a difference of opinion [27]. However, as Blair [28] notes, a minor difference only generates an argument if the difference leads to a controversial assertion about what is right or correct. A version of this was seen in the recent disagreement that erupted when 
an audio clip was heard by some as "Laurel" and others as "Yanni" emphasizing the importance of our acceptance through our senses (in this case, auditory) or signals from the environment. Disagreements of this sort produce arguments because they induce or call for some sort of justification or use of reason.

An argument can also be formally defined as a mode of communication where an individual makes an explicit claim and then supports or thematizes this claim to persuade others to accept it while anticipating criticism [24]. Arguments consequently can be distinguished from non-argumentative discourse by the use of claims, grounds (or evidence) and warrants (links between grounds and claims) as their distinctive mode of communication [23].

Argumentation can be further classified into dialectical and rhetorical forms of argumentation. The dialectical form is a highly structured form of propositional logic that aims to resolve disagreements by applying a set of precisely defined formal rules to test knowledge claims [29]. As a result of this emphasis, dialectical argumentation is intrinsically abstract in its approach, focusing on the testing and derivation of universal truth principles (or "facts") that are unencumbered by the subjective beliefs or preferences pertaining to a particular question or controversy. Dialectical argumentation also focuses more on the relationship between propositional alternatives than the relationship between the propositions and the audience (it transcends, not situates). The dialectic approach to the concern of fake news, consequently, is the development of robust universal principles to assess the factual bases of news stories. It accomplishes its goals by seeking to distil and separate the 'facts' of a story from its non-rational aspects (e.g., the beliefs, opinions, motivations and character of the audience and story teller).

Rhetorical argumentation, on the other hand, focuses on persuasion instead of truth or facts. Instead of examining abstract propositions to their alternatives, rhetorical argumentation focuses on the plausibility of these arguments relative to the audience addressed [30]. Unlike dialectic argumentation, which seeks to attain truth, rhetoric is concerned with attaining shared beliefs or opinions. The rhetorical form of argumentation can be traced to early sophists who asserted that absolute truth was unknowable and perhaps nonexistent and had to be established in each individual case because, as Protagoras of Abdera (who is credited with initiating the Sophist movement) famously stated, "Man is the measure of all things" [31]. Rhetorical argumentation also is associated with pragmatic reasoning as human behavior is dictated by our beliefs.

While rhetorical argumentation is likely to be less precise than dialectic argumentation it is nevertheless governed by norms of appropriateness or pertinence to a particular setting or context. As Leff [30] writes, "To speak well rhetorically as a matter of art is to demonstrate a capacity to adapt to changing local circumstances. In other words, the circumstantial and situated character of rhetoric encourages a norm of accommodation and flexibility - a norm connected with phronesis (practical wisdom) or prudentia (prudence)". As Bons [32] notes, "it is the experience of these [rhetorical insights] and a pragmatic analysis of them which provides one with an empirical stock of knowledge which informs one's opinion and which enables one to respond effectively to the requirements of any given situation".

Rhetorical argumentation consequently serves as a complement to the dialectical approach for addressing the concern of fake news by offering a means of assessing the impact of these stories on resultant belief structures. As Aristotle argued in the beginning of his Rhetoric treatise, rhetoric is the necessary counterpart of dialectic (or "fact-checking") because rhetoric is required to defend proper decisions (you may be right, but you will still need to convince others, otherwise you are to blame [33]).

Indeed, while dialectic and rhetorical approaches seem very much opposed to each other with rhetoric criticized as feigned and unreasonable speech addressed to man's lower instincts, rather than reason, and dialectic described as useless logic chopping, full of sophistry with no practical benefit, they could be construed as complementary sides of the same coin [33]. Leff [30] makes this case when he observes that dialectic is dependent upon rhetoric to "close and define the situations in which it can operate." Rhetoric, he argues, can help provide provisional, local closure when conclusive agreements are not reached through the inferential sequence. On the other side of the coin, Leff suggests that rhetoric needs to be tempered with dialectical rationality if it is to achieve its goal of effective persuasion.

\section{Research method}

\subsection{The empirical context}

To illustrate the import of social representations in understanding how readers react to newsworthy events and news stories, considering their preconceived beliefs and values, we applied this theoretical lens to evaluate the discourse surrounding Roy Moore's candidacy for the U.S. Senate in Alabama in 2017. Roy Moore became the Republican candidate in this election on September 26, 2017 when he defeated Luther Strange in the Republican primary. The Democratic candidate, Doug Jones, eventually defeated Moore in the special election 
held on December 12, 2017. On November 9 the Washington Post reported a news story that stated that Roy Moore initiated sexual encounters with 14-year old Leigh Corfman and other teenage women while in he was in his thirties. In response to the Post story, the media became awash with narratives that offered differing slants on this story. The term "fake news" was also frequently bandied about by participants (from both sides of the political spectrum) when characterizing several of the competing narratives that emerged in the wake of the allegations against Moore. The Post story also piqued national interest in Roy Moore as illustrated by the Google Trends data shown in Figure 1.

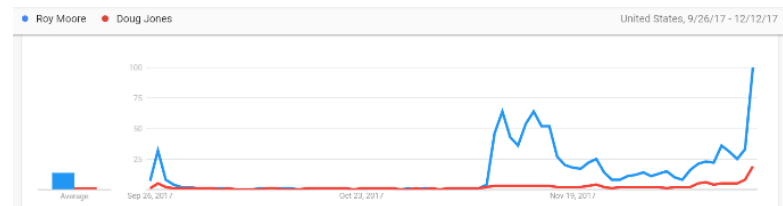

Figure 1. Roy Moore vs. Doug Jones Google searches in the U.S. from 2017-09-26 to 2017-12-12.

To investigate different social representations of reactions to these events, we examined the most relevant news stories about Roy Moore - as identified by the Google Search Page Rank algorithm [34] - on a left leaning news site (Daily Kos) and a right leaning news site (Breitbart) and analyzed the resultant discourse and rhetoric on each site. According to Wikipedia, these sites can be characterized as follows:

- Daily Kos - is a group blog and internet forum focused on liberal American politics. It is sometimes considered an example of "netroots" activism.

- Breitbart - is a far-right syndicated American news, opinion and commentary website founded in mid2007 by conservative commentator Andrew Breitbart, who conceived it as "the Huffington Post of the right."

Analysis of these news sites with respect to their political bias $[5,6]$ categorizes Daily Kos as hyperpartisan to the left and Breitbart as slightly more extreme and to the right, specifically as "most extreme right", e.g. see http://mediabiaschart.com. Analysis of these sites by the same sources also gives Daily Kos slightly higher marks for journalistic quality when compared with Breitbart. Because of the differences between these sites this study presumed two opposite biases:

- Bias 1: Roy Moore was an unworthy candidate for election to the U.S. Senate in Alabama in 2017. (This bias was presumed to be held by the majority of the Daily Kos readership.)
- Bias 2: Roy Moore was a worthy candidate for election to the U.S. Senate in Alabama in 2017. (This bias was presumed to be held by the majority of the Breitbart readership.)

We analyzed the discourse on both news sites (as it appeared in reader comments) from September 26 to December 12, 2017, to look for rhetorical practices that were unlikely to be flagged by fact-checkers. The analysis was meant to examine the impact of newsworthy events that confirm or challenge the presumed reader bias on the social representation process by noting the presence or absence of argumentation in reader comments. If arguments in comments adhered to the norms of well-formed and pragmatically reasoned arguments, they were categorized as non-fallacious, regardless of their believability. Comments posted in response to news stories were categorized as fallacious if the form and substance of arguments they contained matched one or more of the 18 rhetorical practices described as the "core' informal fallacies or the "Gang of 18" [35].

\subsection{Data collection and analysis}

The news articles that define our data set were determined by having Google Search identify the 40 articles most relevant to Roy Moore. We used three significant and relevant events to define and delineate the time periods examined. These were:

- Event 1: Roy Moore becomes the Republican candidate in the special election for U.S. Senate in Alabama (September 26, 2017);

- Event 2: The Washington Post publishes a story alleging sexual misconduct by Moore in his thirties (November 9, 2017); and

- Event 3: The special election for the open U.S. Senate seat is held (December 12, 2017).

With representation from both sides of the political spectrum and with these three events, we defined four sets of relevant online news stories. Here, we operationalized "relevance" of a story to determine the placement of a story in the "top 10" using Google's Page Rank algorithm on the morning of June 5, 2018.

Table 1. Identification of data set

\begin{tabular}{|c|c|c|c|c|c|}
\hline Source & \multicolumn{2}{|c|}{ Time Period 1} & \multicolumn{3}{|c|}{ Time Period 2} \\
\hline Daily Kos & $\mathrm{E}$ & Set $A^{1}$ & 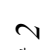 & Set B & $n$ \\
\hline Breitbart & 可 & Set $\mathrm{C}$ & 这 & Set $D^{2}$ & 幽 \\
\hline
\end{tabular}

1. See p. 1 at http://bit.ly/roy-moore-2017-case

2. See p. 4 at http://bit.ly/roy-moore-2017-case 
Following this identification, each article was given a unique identifier (within the data set) as specified in the PDF document pointed to by the bit.ly links above, i.e. $\mathrm{A} 1, \mathrm{~A} 2, \ldots, \mathrm{A} 10, \mathrm{~B} 1, \mathrm{~B} 2, \ldots, \mathrm{B} 10, \ldots, \mathrm{D} 1, \mathrm{D} 2, \ldots$ D10. Of the 20 Daily Kos articles in sets A and B, 19 confirmed Bias 1 and one was neutral with respect to Bias 1. Of the 20 Breitbart articles in sets $\mathrm{C}$ and D, 16 confirmed Bias 2, three were neutral with respect to Bias 2, and one challenged Bias 2. The Breitbart story that challenged Bias 2 (D2) was breaking coverage of Event 3, which reported that "Establishment Republicans Cheer Roy Moore's Loss in Alabama".

For each online news story, we characterized social representations (of narrative, discourse and rhetoric) as follows:

First, we visualized the four sets of news stories as word clouds to gauge to what extent the narratives at Daily Kos and Breitbart changed in the wake of Moore's nomination and then the Washington Post news story.

Second, and in order to balance the social representations reflected by each of our 40 stories, we analyzed the first 15 most liked comments for each story (or all comments if there were fewer than 15 comments) as follows: Does the comment contain an argument? If not, categorize it as non-argumentative, i.e. devoid of argumentation. If it contains one or more argument, i.e. reflects argumentation, then categorize each argument as either fallacious (identified as one of the Gang of 18 rhetorical fallacies) or non-fallacious. This analysis yielded a total of 274 non-argumentative comments and 299 comments that contained arguments. Of these 299 comments, 150 contained one or more fallacious argument and 149 contained exclusively well-formed and pragmatically reasoned arguments. Because categorization of fallacious arguments is both subjective and challenging [40, 42], $\mathrm{Yu}$ and $\mathrm{Zhan}$ led this effort in frequent consultation with one or more of the first three authors. This method of categorization of fallacies via collaboration and conversation was used in favor of inter-rater reliability. With that said, reliable fallacy identification is central to the main findings presented in the remainder of this paper but precise fallacy categorization is not. Table 2 shows illustrative examples for seven of the 18 types of fallacy [35]. These seven types of rhetorical fallacy accounted for approximately $84 \%$ of the fallacies found in reader comments on the news stories that defined our data set.

\section{Findings}

\subsection{News sources and news stories}

To get a sense of the social representations in the narratives at Daily Kos and Breitbart and how they changed after Roy Moore's nomination (Event 1 ) and then after the Washington Post story (Event 2), we visualized each set of 10 news stories as a word cloud. Because they provided obvious context and were at the epicenter of our study, the following words were removed from the clouds shown in Figure 2: "Roy," "Moore," and "Alabama." These word clouds illustrate important context for understanding the discourse and rhetoric [36] within each time period (see Section 3.2 for descriptions of the Events and the Time Periods).

The four word clouds in Figure 2 are visually quite different. Although it is difficult to infer a cohesive narrative from any of these word clouds, it is interesting to explore how the dominant words are used. The words "Law," "Trump," and "Year" dominate all other words as indicated by their size.
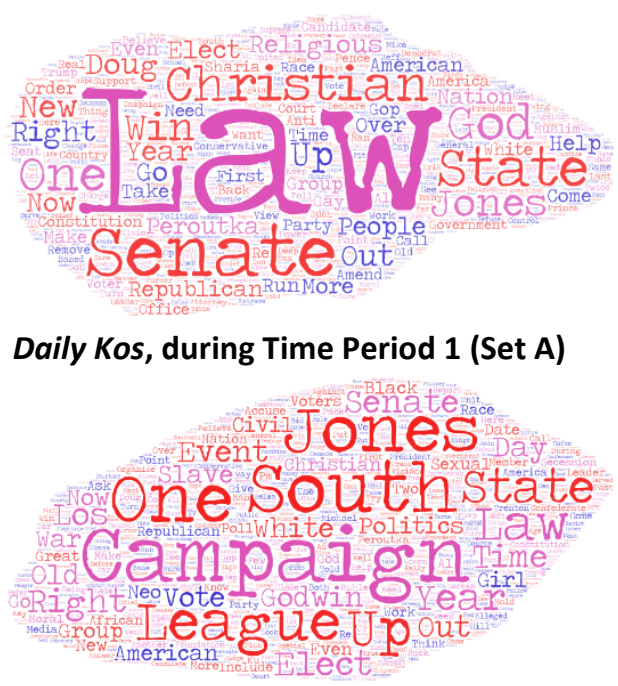

Daily Kos, during Time Period 2 (Set B)

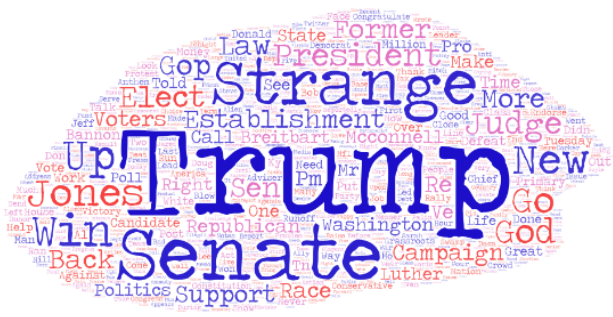

Breitbart, during Time Period 1 (Set C)

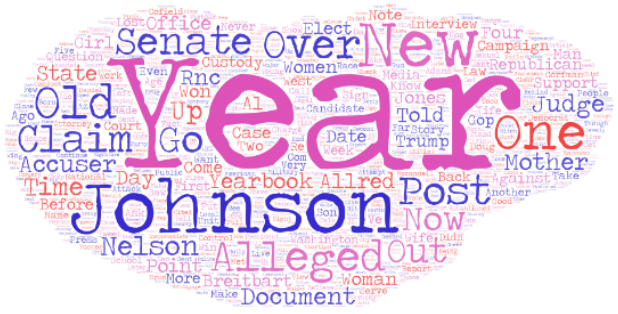

Breitbart, during Time Period 2 (Set D)

Figure 2. Word clouds for news stories in each set 
Table 2. Select list of deceitful rhetorical practices from "Gang of 18" core fallacies [35]

\begin{tabular}{|c|c|c|}
\hline $\begin{array}{l}\text { Deceitful rhetorical practice, } \\
\text { aka fallacy }\end{array}$ & $\begin{array}{l}\text { Example from Daily Kos } \\
\text { comments, Article ID (date) }\end{array}$ & $\begin{array}{l}\text { Example from Breitbart comments, } \\
\text { Article ID (date) }\end{array}$ \\
\hline $\begin{array}{l}\text { ad baculum - When one appeals } \\
\text { to force or the threat of force to } \\
\text { bring about the acceptance of a } \\
\text { conclusion. }\end{array}$ & $\begin{array}{l}\text { How many law suits could be } \\
\text { expected to try to bring individual } \\
\text { schools from really, really crappy } \\
\text { to just really crappy? If you cared } \\
\text { about your kids' education and } \\
\text { you had any choice, you wouldn't } \\
\text { live in Alabama in the first place. } \\
\text { A1 (October 13, 2017) }\end{array}$ & $\begin{array}{l}\text { The whole 'pervert' thing is a red } \\
\text { herring. Democrats blatantly cheated } \\
\text { in Alabama. Anyone willing to give a } \\
\text { seat to Dems over accusations of the } \\
\text { nature lodged against Moore is a } \\
\text { moron (...and most likely an actual } \\
\text { Dem). } \\
\text { D7 (December 12, 2017) }\end{array}$ \\
\hline $\begin{array}{l}\text { ad hominem - When one attacks } \\
\text { the character or circumstances of } \\
\text { an individual instead of seeking } \\
\text { to contest the soundness of the } \\
\text { argument. }\end{array}$ & $\begin{array}{l}\text { Moore will accomplish absolutely } \\
\text { nothing if he wins - since he is a } \\
\text { carbon copy of the nitwit he is } \\
\text { replacing. } \\
\text { A3 (October 12, 2017) }\end{array}$ & $\begin{array}{l}\text { McCain is unfit to serve. Letting a } \\
\text { man with freaking brain cancer make } \\
\text { policy decisions that affect the } \\
\text { ENTIRE country? } \\
\text { C5 (September 27, 2017) }\end{array}$ \\
\hline $\begin{array}{l}\text { begging the question - The } \\
\text { fallacy that is committed when } \\
\text { the conclusion of an argument is } \\
\text { assumed in one of its premises. }\end{array}$ & $\begin{array}{l}\text { How the heck did Moore manage } \\
\text { to graduate from law school and } \\
\text { pass the (probably very weak and } \\
\text { easy) Alabama bar exam. Must } \\
\text { have cut the Constitutional law } \\
\text { classes. } \\
\text { A6 (October 21, 2017) }\end{array}$ & $\begin{array}{l}\text { We need more focused, effective } \\
\text { leaders who are not afraid to rock the } \\
\text { boat to get things done. More fighters } \\
\text { than go along wimps, some who will } \\
\text { do what it takes such as eliminate the } \\
\text { filibuster if necessary. } \\
\text { C4 (September 26, 2017) }\end{array}$ \\
\hline $\begin{array}{l}\text { complex question - A question } \\
\text { that (1) depends on a } \\
\text { questionable assumption, and (2) } \\
\text { whose answer(s) necessarily } \\
\text { appear to endorse this } \\
\text { assumption. }\end{array}$ & $\begin{array}{l}\text { So how does eliminating a } \\
\text { constitutional provision that } \\
\text { requires separate schools (that you } \\
\text { are prohibited by law from setting } \\
\text { up in any case), cause an } \\
\text { "enormous tax increase"? } \\
\text { A1 (October 13, 2017) }\end{array}$ & $\begin{array}{l}\text { Where are the politicians representing } \\
\text { American citizens? Why do citizens } \\
\text { have zero say in our hard earned tax } \\
\text { money being spent on people that } \\
\text { have ZERO rights in this country? } \\
\text { Where are the people in CHARGE? } \\
\text { C4 (September 26, 2017) }\end{array}$ \\
\hline $\begin{array}{l}\text { composition and division - The } \\
\text { fallacy of composition arises } \\
\text { when one infers that something is } \\
\text { true of the whole from the fact } \\
\text { that it is true of some part of the } \\
\text { whole. Conversely, the fallacy of } \\
\text { division occurs when one infers } \\
\text { that something true for the whole } \\
\text { must also be true of all or some of } \\
\text { its parts. }\end{array}$ & $\begin{array}{l}\text { Today's evangelicals openly state } \\
\text { that it's worth looking the other } \\
\text { way to achieve other objectives, } \\
\text { hence they champion Trump } \\
\text { because Gorsuck. They probably } \\
\text { believe Roy Moore is the real deal, } \\
\text { a man of God. } \\
\text { A2 (September 28, 2017) }\end{array}$ & $\begin{array}{l}\text { If Alabama is prepared to elect a far } \\
\text { left zealot to punish a man for liking } \\
\text { younger women in an era when it was } \\
\text { far more socially acceptable than } \\
\text { today, then America is truly lost. }\end{array}$ \\
\hline $\begin{array}{l}\text { faulty analogy - This fallacy } \\
\text { consists in assuming that because } \\
\text { two things are alike in one or } \\
\text { more respect, they are necessarily } \\
\text { alike in some other respect. }\end{array}$ & $\begin{array}{l}\text { I'm sure the "mainstream" } \\
\text { Republicans are outraged and will } \\
\text { speak out forcefully against all of } \\
\text { his [Roy Moore's] outrageous } \\
\text { views just like they are doing with } \\
\text { Donald Tru.......oh wait. } \\
\text { A7 (September 27, 2017) }\end{array}$ & $\begin{array}{l}\text { Like leaving heavan and going to hell. } \\
\text { I won a sales contest a few years ago } \\
\text { and the prize was a trip to NYC. I told } \\
\text { them i live in Texas. Going to NYC is } \\
\text { punishment. The gave me cash to go } \\
\text { wherever i went. I spent a week at a } \\
\text { Texas lake resort. } \\
\text { C1 (September 26, 2017) }\end{array}$ \\
\hline $\begin{array}{l}\text { secundium quid - This fallacy } \\
\text { occurs when an attempt is made } \\
\text { to apply a general rule to all } \\
\text { situations when there are clear } \\
\text { exceptions to the rule. }\end{array}$ & $\begin{array}{l}\text { Sounds like just the sort of things } \\
\text { Democrats would do if Democrats } \\
\text { did that sort of thing (but since } \\
\text { they don't ...) } \\
\text { B2 (November 28, 2017) }\end{array}$ & $\begin{array}{l}\text { Then multiple witnesses started } \\
\text { coming forward to verify the whole } \\
\text { thing was a scam... Roy Moore was } \\
\text { the victim of a scam. } \\
\text { D4 (December } 8, \mathbf{2 0 1 7} \text { ) }\end{array}$ \\
\hline
\end{tabular}




\subsection{1 "Law" in Daily Kos, Time Period 1}

Before the Washington Post story, most Daily Kos articles were concerned with Roy Moore's political ideas and his associations with social and political organizations. Given this context, it was common for Moore to speak publically about the law of God, U.S. law, religious law, moral law, anti-immigrant law, laws about homosexuality, Islamic law, etc. His comments were quoted by many authors. In addition, the Southern Poverty Law Center was mentioned several times. Finally, Moore had been both a lawyer and a judge and had written some controversial (in the eyes of the Daily Kos readership, who likely held Bias 1) opinions about law, legal interpretations and court rulings.

\subsection{2 "Trump" in Breitbart, Time Period 1}

Some authors of stories on Breitbart mentioned Trump when comparing him to Roy Moore. Moore's support of Trump as well as his disagreements with Trump were also mentioned several times. In other situations, authors talked about Trump as he supported Moore's opponent Luther Strange (before the Republican primary), congratulated Moore on his win in the primary (Event 1), and then supported Moore in his race against Democrat Doug Jones.

\subsection{3 "Year" in Breitbart, Time Period 2}

After the Washington Post story, most Breitbart news stories defended Roy Moore against the accusations of sexual misconduct with teenage girls and also confirmed Bias 2. To be more specific, in defending Moore many authors described the accusations in detail including the age of the girls (and Moore's age) by "years old". Furthermore, when describing Moore's past or his relationship with social and political organizations, authors often used phrases like "several years ago," "15 years," etc.

\subsection{Social representations across the sets}

Because the narratives at Daily Kos and Breitbart and the presumed core values of their readerships are different, we also expected the nature and form of the respective social representations to be different. For the 573 comments analyzed in this study, however, we did not find this to be the case. Our analysis (summarized in Figures 3 and 4) shows that the nature and form of social representations reflected by the reader comments on these websites were surprisingly similar.

Figure 3 presents bar graphs showing the number of argumentative vs. non-argumentative comments associated with our 20 most relevant news stories from each website (Sets A and B for Daily Kos; Sets C and D for Breitbart) across our two time periods. The left bars in graphs 3(a) and 3(b) show the number of nonargumentative comments whereas the right (stacked) bars show the number of comments that contain arguments. Comments containing fallacious arguments are tallied in red within the right-hand bar in each graph and non-fallacious comments are tallied in green.

Based on the biases (and underlying assumptions) expressed earlier as Bias 1 and Bias 2, it is reasonable to infer that the "rigid" core values of the majority of Daily Kos and Breitbart readers were challenged or confirmed by the watershed Roy Moore news stories of 2017 as follows:

- The core values of the left-leaning Daily Kos readership were challenged by the nomination of Roy Moore instead of Luther Strange on Sept. 26 since this event (Event 1) is in conflict with Bias 1;

- The core values of the left-leaning Daily Kos readership were confirmed by the Washington Post story published on Nov. 9 since this event (Event 2) is positively aligned with Bias 1;

- The core values of the right-leaning Breitbart readership were confirmed by the nomination of Roy Moore as the Republican candidate for the U.S. Senate since this event (Event 1) is positively aligned with Bias 2; and

- The core values of the right-leaning Breitbart readership were challenged by the Washington Post story alleging sexual misconduct by Moore since this event (Event 2) is in conflict with Bias 2.

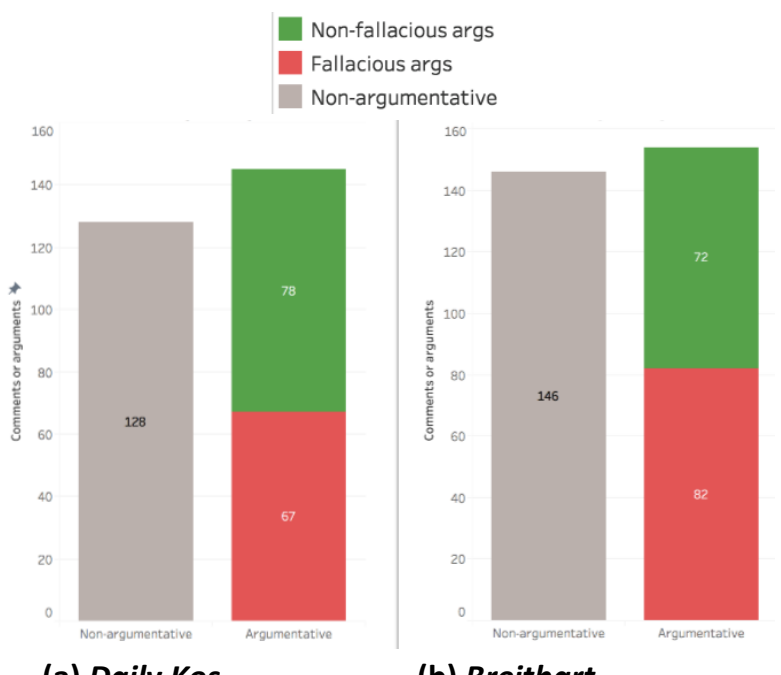

(a) Daily Kos

(b) Breitbart

Figure 3. Social representations via reader comments for Daily Kos and Breitbart aggregated across both time periods

Based on these inferences (aligned in time with the events described earlier in Section 3.2), we divided the data presented in Figure 3 into the two time periods that are bounded by these significant and relevant events.

Figure 4 presents bar graphs similar those in Figure 3 when the presumed core values and bias of the readership of each site are challenged [in Figure 4(a) and 
Figure 4(d)] as well as when the presumed bias of most readers is confirmed [in Figure 4(b) and Figure 4(c)].

Based on analysis of the social representations in reader comments, the proportion of non-argumentative discourse varied over the course of the study as shown in Figure 4. Since non-argumentative discourse is associated with the concept of the rigid "core" of a social representation (not receptive to contravening evidence), this finding suggests that even in extremely partisan representations of news stories readers show a willingness to adjust the boundaries of their beliefs after the occurrence of significant and relevant events. This willingness to adjust the boundaries of their "beliefs" does not mean that they are willing to abandon their values or beliefs in response to such events or subsequent news stories. This is supported by the presence of significant levels of non-argumentative discourse throughout the study. This finding supports previous work $[7,8]$ that has shown the tendency to discount facts that are not aligned with preconceived beliefs (confirmation bias).

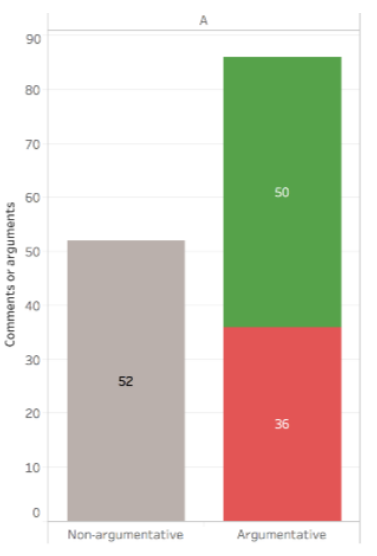

(a) Daily Kos, Time Period 1

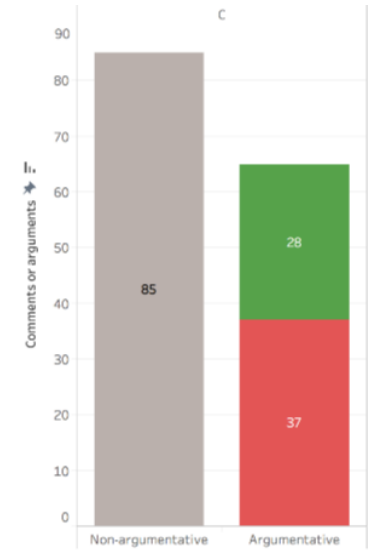

(c) Breitbart, Time Period 1

Figure 4. Social representations via reader comments for Daily Kos and Breitbart separated across time periods
Figure 4 provides evidence for two additional findings based on the social representations reflected in the comments. First, in the wake of significant events that confirmed the presumed bias of most readers, we observed more non-argumentative vs. argumentative comments and the same stories yielded a greater proportion of fallacies within the total number of arguments. Second, in the wake of significant events that challenged the presumed bias of most readers, we observed more argumentative vs. non-argumentative comments. Furthermore, these arguments contained proportionally fewer fallacies than non-fallacies. Specifically, the link between confirming (vs. challenging) biases and the greater number of nonargumentative comments can be observed by the increase in height of the left-hand bar in graph 4(b) - for Daily Kos - when compared with the same bar in graph 4(a) and the increase in height of the left-hand bar in graph 4(c) - for Breitbart - relative to the same bar in graph 4(d). And the link between challenging biases and the proportional decrease in the number of fallacies can be observed by the increase in the ratio of green (argumentative but non-fallacious comments) to red (fallacious comments) when comparing the right-hand bars in graphs 4(a) with 4(b) - for Daily Kos - and the right-hand bars in graphs 4(d) with 4(c) - for Breitbart.

\section{Discussion, implications and limitations}

Our findings extend previous work by showing that the boundaries of confirmation bias can be flexible. Specifically, our work shows that readers on both sides of the political spectrum tend to be more deliberative in response to news that challenges their biases than when faced with significant events or news stories that simply confirm these biases. This is indicated by the increase in argumentation and a corresponding reduction in the amount of fallacious argumentation in the wake of contravening events and subsequent news stories.

An important limitation of our findings, however, is that the identification of "fallacy" or "fallacious argumentation" is a difficult exercise as this is a subjective process that is heavily dependent on the context of the discourse. While abstract definitions and examples of fallacious reasoning may help lend insight into the shortcomings of these types of argument, research has shown that what is viewed as fallacious in one context could constitute sound inference in another [40-42]. We therefore adopt an interpretive stance in our approach to the identification of fallacies that acknowledges that our conceptualization of these fallacies is informed by our particular understanding of the context and purpose of this discourse. Our study consequently is not designed to provide a definitive 
representation of the domain, but to lend justifiable insights into particular discourse and rhetoric.

Another limitation of our findings is that although social representations reflected in reader comments are associated with specific news stories, these representations are likely influenced by factors other than any single article or the online discourse that surrounds it. Clearly such external factors include the psychological effect of significant and relevant newsworthy events, e.g. Event 1, Event 2 and Event 3, on the comment authors. This study, however, does not attempt to distinguish between the effect of different factors on these social representations.

In the IS literature, social representations theory has primarily been used as a heuristic device for analyzing how differences and similarities in group sense-making activities impact the implementation and adoption of information systems in organizations [16, 37]. Most work in this domain consequently has focused on eliciting and examining the content of varying group representations and examining how these representations impact the enactment of technologies $[19,21,38]$. Our findings extend this research by going beyond examination of content to an explanation of the dynamics of changes in these representations. Specifically, we apply argument theory to demonstrate how the boundaries of core and peripheral elements of social representations are negotiated within the readership of online news stories.

Our work also contributes to the IS literature on fake news by expanding the reach of these studies beyond investigations of how information systems could help control the dissemination of fake news (i.e. addressing the source) to include addressing challenges in how readers consume and react to news stories that may be factually questionable. Specifically, our work suggests that information systems might be useful aids in the negotiation of the boundaries of confirmation bias relative to significant, newsworthy events and subsequent news stories.

\section{Concluding remarks}

We conclude by returning to one of our findings: readers of online news stories are willing to engage in argumentative (or "reasoned") discourse even though they hold fast to a core set of obdurate beliefs. Adoption of fallacy detection mechanisms, however, might enrich, expand and even improve this discourse without violating the core beliefs of the discourse participants. Unlike fact-checking, which independently assesses the veracity of a claim based on universal standards, a fallacy-check allows for arguments that are based on doxa or subjective beliefs, e.g. Bias 1 and Bias 2, but assesses them based on their form, content and internal consistency.

This study points to possibilities for behavioral and technological interventions as novel approaches to help alleviate the fake news problem and its consequences. Behavioral interventions such as encouragements to visit and appreciate a varied set of outlets across the political spectrum allows news readers to gain exposure to different perspectives. Here, we find recent work [5, 6] useful in understanding how different sources may be positioned along two dimensions: journalistic quality and partisan bias.

Finally, our study confirms that for readers of online news stories from outlets that rely on persuasive argumentation mere fact-checking will not be sufficient to address important problems, including confirmation bias. Behavioral and technological interventions may, then, be needed to provide helpful alerts to readers of news stories published by different outlets. Whether and how initiatives to identify fallacies, for example, can be designed, rolled out, and empirically tested remains part of a larger research agenda that we hope will be enticing to research communities in a multitude of disciplines.

\section{Acknowledgments}

The authors gratefully acknowledge feedback, suggestions and comments on earlier versions of this work from Randy Minas, Anthony Valenti and Ian Yates, and also our anonymous reviewers. Their thoughts and insights significantly improved this paper.

\section{References}

[1] Allcott, H. \& M. Gentzkow, Social media and fake news in the 2016 election. J. of Economic Perspectives, 2017. 31(2): p. 211-236.

[2] Kim, A. \& A.R. Dennis, Says Who?: How News Presentation Format Influences Perceived Believability and the Engagement Level of Social Media Users. 2017, at http://dx.doi.org/10.2139/ssrn.2987866.

[3] Silverman, C., Here are 50 of the biggest fake news hits on Facebook from $2016 . \quad$ BuzzFeed, https://www.buzzfeed.com/craigsilverman/top-fake-newsof-2016, 2016.

[4] Wintersieck, A.L., Debating the truth: The impact of fact-checking during electoral debates. American Politics Research, 2017. 45(2): p. 304-331.

[5] Rubin, J.S. How Not to Think About Fake News. American Anthropologist Website, 2017.

[6] Little, H.B., Bias: Left, Right, Center, Fringe, and Citing Snapchat, in Information Bias. 2017, J. of the American Association of School Librarians.

[7] McKenzie, C.R., Increased sensitivity to differentially diagnostic answers using familiar materials: Implications 
for confirmation bias. Memory \& Cognition, 2006. 34(3): p. $577-588$.

[8] Koslowski, B., Scientific reasoning: Explanation, confirmation bias, and scientific practice. Handbook of the psychology of science, 2012: p. 151-192.

[9] Moscovici, S., The phenomenon of social representations. S. 3-70 in: Robert M. Farr und Serge Moscovici (Eds.): Social representations. 1984, Cambridge, London, New York: Cambridge University Press.

[10] Moscovici, S., Social representations: Explorations in social psychology. 2001: New York University Press.

[11] Moscovici, S., Attitudes and opinions. Annual review of psychology, 1963. 14(1): p. 231-260.

[12] Durkheim, E., 1995). The Elementary Forms of the Religious Life, trans. Karen Fields. 1912, New York: Free Press.

[13] Lorenzi- Cioldi, F. \& A. Clémence, Group processes and the construction of social representations. 2001: Wiley Online Library.

[14] Pawlowski, S.D., E.A. Kaganer, \& J.J. Cater, Focusing the research agenda on burnout in IT: social representations of burnout in the profession. European $\mathrm{J}$. of Information Systems, 2007. 16(5): p. 612-627.

[15] Moscovici, S. \& I. Marková, Presenting social representations: A conversation. Culture \& psychology, 1998. 4(3): p. 371-410.

[16] Gal, U. \& N. Berente, A social representations perspective on information systems implementation: Rethinking the concept of "frames". Information technology \& people, 2008. 21(2): p. 133-154.

[17] Voelklein, C. \& C. Howarth, A review of controversies about social representations theory: A British debate. Culture \& psychology, 2005. 11(4): p. 431-454.

[18] Markova, I., Amédée or how to get rid of it: Social representations from a dialogical perspective. Culture \& Psychology, 2000. 6(4): p. 419-460.

[19] Kaganer, E.A. \& E. Vaast. Responding to the (almost) unknown: Social representations and corporate policies of social media. In ICIS 2010.

[20] Abric, J.-C., A structural approach to social representations, in Representations of the social: Bridging theoretical traditions. 2001, Blackwell Publishing: Malden, p. 42-47.

[21] Jung, Y., S.D. Pawlowski, \& S. Wiley-Patton, Conducting social cognition research in IS: A methodology for eliciting and analyzing social representations. Communications of the Association for Information Systems, 2009. 24(35): p. 597-614.

[22] Flament, C., Consensus, salience and necessity in social representations-Technical note. Papers on social representations, 1994. 3: p. 97-105.

[23] Toulmin, S., The Uses of Argument. 1958, Cambridge: Cambridge University Press.

[24] Habermas, J., The Theory of Communicative Action (Vol. 1). 1984, Boston: Beacon Press.
[25] Eemeren, F.H., et al., Fundamentals of argumentation theory: A handbook of historical backgrounds and contemporary developments. 1996, Dordrecht: Kluwer Academic Publishers.

[26] Hirschheim, R., Information systems epistemology: An historical perspective. Research methods in information systems, 1985: p. 13-35.

[27] Eemeren, F.v., The Study of Argumentation, in The SAGE Handbook of Rhetorical Studies. 2009, Sage Publications: Thousand Oaks, CA. p. 109-124.

[28] Blair, J.A., A time for argument theory integration, in Groundwork in the Theory of Argumentation. 2012, Springer: Netherlands. p. 197-203.

[29] Rowland, R.C., On defining argument. Philosophy \& Rhetoric, 1987: p. 140-159.

[30] Leff, M., The relation between dialectic and rhetoric in a classical and a modern perspective, in Dialectic and Rhetoric. 2002, Springer: p. 53-63.

[31] Foss, S.K., K.A. Foss, \& R. Trapp, Contemporary perspectives on rhetoric. 2014, Waveland Press.

[32] Bons, J., Reasonable Argument before Aristotle: The Root of The Enthymeme. Dialectic and Rhetoric. 2002, p. 16.

[33] Krabbe, E.C., Meeting in the house of Callias: Rhetoric and dialectic. Argumentation, 2000. 14(3): p. 205-217.

[34] Brin, S. \& L. Page, The anatomy of a large-scale hypertextual web search engine. Computer networks and ISDN systems, 1998. 30(1-7): p. 107-117.

[35] Woods, J.H., The death of argument: Fallacies in agent based reasoning, Vol. 32. 2004: Springer Science \& Business Media.

[36] Figueira, A., M. Sandim, \& P. Fortuna, An approach to relevancy detection: contributions to the automatic detection of relevance in social networks, in New Advances in Information Systems and Technologies. 2016, Springer: p. 89-99.

[37] Ellway, B.P. \& G. Walsham, A doxa-informed practice analysis: reflexivity and representations, technology and action. Information Systems J., 2015. 25(2): p. 133-160.

[38] Pozzebon, M., M.A. Cunha, \& T.R. Coelho, Making sense to decreasing citizen eParticipation through a social representation lens. Information and Organization, 2016. 26(3): p. 84-99.

[39] Garrett, R.K., Echo chambers online?: Politically motivated selective exposure among Internet news users. J. of Computer-Mediated Communication, 2009. 14(2): p. 265-285.

[40] Boudry, M., F. Paglieri, \& M. Pigliucci, The fake, the flimsy, and the fallacious: Demarcating arguments in real life. Argumentation, 2015. 29(4): p. 431-456.

[41] Stone, M.A., Denying the antecedent: Its effective use in argumentation. Informal Logic, 2012. 32(3): p. 327-356. [42] Metcalf, R., Rethinking the ad hominem: A case study of Chomsky. Argumentation, 2005. 19(1): p. 29-52. 